\title{
Ethyl pyruvate induces necrosis-to-apoptosis switch and inhibits high mobility group box protein 1 release in A549 lung adenocarcinoma cells
}

\author{
SUNG-CHUL LIM ${ }^{1,2}$, JEONG EUN CHOI ${ }^{1}$, CHO HEE KIM $^{3}$, HONG-QUAN DUONG ${ }^{1}$, \\ GUI-AE JEONG ${ }^{1}$, HO SUNG KANG ${ }^{3}$ and SONG IY HAN ${ }^{1}$ \\ ${ }^{1}$ Research Center for Resistant Cells and ${ }^{2}$ Department of Pathology, College of Medicine, Chosun University, \\ Gwangju 501-759; ${ }^{3}$ Department of Molecular Biology, College of Natural Sciences, and \\ Research Institute of Genetic Engineering, Pusan National University, Pusan 609-735, Korea
}

Received March 12, 2007; Accepted April 16, 2007

\begin{abstract}
Ethyl pyruvate (EP), a stable lipophilic pyruvate derivative, has been shown to exert anti-inflammatory activities through inhibiting the expression of various pro-inflammatory mediators as well as circulating levels of high mobility group box protein 1 (HMGB1) in a variety of in vitro and in vivo model systems. Necrotic cell death triggers an inflammatory response through release of HMGB1 in the extracellular space due to the membrane rupture. In an effort to better understand the pharmacological action mechanism that could explain the anti-inflammatory properties of EP, we examined the effects of EP on necrotic cell death in A549 lung adenocarcinoma cells in response to glucose deprivation (GD), a common characteristic of the tumor microenvironment. Here we show that EP prevented GD-induced necrosis and HMGB1 release and switched the cell death mode to apoptosis through inhibiting GD-induced $\mathrm{CuZn}$ superoxide dismutase release and ROS production. These results suggest that the necrosisto-apoptosis switch activity of EP may contribute to its anti-inflammatory action and that EP may suppress tumor development possibly through its activity to induce the cell death mode switch from tumor promoting necrotic cell death to tumor suppressive apoptotic cell death.
\end{abstract}

\section{Introduction}

Ethyl pyruvate (EP), a simple aliphatic ester derived from the endogenous metabolite pyruvic acid, has recently been reported

Correspondence to: Dr Ho Sung Kang, Department of Molecular Biology, College of Natural Sciences, Pusan National University, Pusan 609-735, Korea

E-mail: hspkang@pusan.ac.kr

Dr Song Iy Han, Research Center for Resistant Cells, College of Medicine, Chosun University, Gwangju 501-759, Korea

E-mail:sihan@chosun.ac.kr

Key words: ethyl pyruvate, necrosis, apoptosis, high mobility group box protein $1, \mathrm{CuZn}$ superoxide dismutase to prevent lethality in mice with established lethal sepsis and systemic inflammation (1-3). It also is an experimental therapy that effectively protects animals from acute endotoxemia and bacterial peritonitis (4) and ischemia reperfusion-induced tissue injury (5-6). This protective effect of EP is related to its anti-inflammatory action. EP down-regulates a number of proinflammatory genes including tumor necrosis factor (TNF), cyclooxygenase-2 (COX-2), and interleukin (IL)-6, in a variety of in vitro and in vivo model systems $(2,7)$. In addition, EP treatment of septic mice decreases circulating levels of high mobility group box protein 1 (HMGB1). HMGB1 is a major nonhistone chromosomal protein thought to be implicated in transcription, replication and recombination as well as in chromatin organization, but acts as a potent proinflammatory mediator and causes inflammatory responses when present extracellularly (8-10). However, the biochemical basis for the anti-inflammatory actions of pyruvate remains to be further elucidated.

In most cases, inflammation is linked to necrotic cell death that occurs by a number of insults such as oxidative stress (10-12). Unlike apoptosis, where the cell content remains packed in the apoptotic bodies that are removed by macrophages, and thereby inflammation does not occur, during necrosis, the cell membrane is ruptured, and the cytosolic constituents including HMGB1 are released into the extracellular space causing a massive inflammatory response (8-12). Thus, the consequences of apoptosis and necrosis are quite different for a whole organism. One of the main necrotic cell death-inducing stimuli is oxidative stress (13). Upon oxidative stress, the membrane permeability transition (MPT) of mitochondria initiates a series of events that culminate in either apoptosis or necrosis, most notably depending on the levels of ATP, and $\mathrm{Ca}^{2+}$ (14-16). Cellular damage by ROS is compromised by the levels of defense antioxidant enzymes such as cytosolic $\mathrm{CuZn}$ superoxide dismutase (CuZnSOD), mitochondrial MnSOD, glutathione peroxidase (GPx), and catalase (17). Cytosolic CuZnSOD and mitochondrial MnSOD efficiently detoxify $\mathrm{O}_{2}{ }^{-}$formed on both sides of mitochondrial inner membranes initially to $\mathrm{H}_{2} \mathrm{O}_{2}$, which in turn is further converted to $\mathrm{H}_{2} \mathrm{O}$, with the help 
of GPx and catalase. Previously, we demonstrated that A549 lung adenocarcinoma cells undergo necrotic cell death and HMGB1 release in response to glucose deprivation (GD), a common characteristic of the tumor microenvironment (18), through production of ROS (19). Recently, we also found that $\mathrm{CuZnSOD}$ is released into the extracellular space in an active form upon GD, possibly to accelerate ROS (possibly $\mathrm{O}_{2}^{-}$) damage and to facilitate necrotic cell death (manuscript submitted).

In the present study, to gain a better understanding of the molecular basis for the anti-inflammatory effects of EP, we examined the effects of EP on GD-induced necrotic cell death and HMGB1 release and show that EP prevented HMGB1 release by inducing the switch from GD-induced necrosis to apoptosis through prevention of GD-induced CuZnSOD release and ROS production. Thus, in addition to inhibiting active secretion of HMGB1 by macrophages, EP appeared to have potential to suppress HMGB1 release from necrotic cells, thereby contributing to its ability to prevent inflammatory response.

\section{Materials and methods}

Cell culture and glucose deprivation. Human lung adenocarcinoma cell line A549 cells were obtained from American Type Culture Collection and grown in RPMI-1640 media (Gibco BRL) supplemented with $10 \%(\mathrm{v} / \mathrm{v})$ heat-inactivated fetal bovine serum (FBS, Gibco BRL) and $1 \%$ penicillinstreptomycin (PS, Gibco BRL) in a $37^{\circ} \mathrm{C}$ humidified incubator with $5 \% \mathrm{CO}_{2}$. For glucose deprivation, cells were gently rinsed twice with glucose-free RPMI-1640 and incubated in GD medium [glucose-free RPMI-1640 medium (Gibco BRL) containing $10 \%$ dialyzed and heat-inactivated FBS and $1 \%$ PS].

Western blot analysis, enzyme activity assay and transcriptionpolymerase chain reaction (RT-PCR). Western blotting with antibodies to PARP (Santa Cruz), active caspase-3, active caspase-9 (Cell signaling), CuZnSOD, MnSOD, catalase (Santa Cruz), ERK2 (Cell Signaling), and HMGB1 (BD Pharmingen) was performed as described previously (19). SOD activity was monitored by nitroblue tetrazolium negative staining after native gel electrophoresis on $7 \%$ polyacrylamide gels as described previously (19). The lower band was preconfirmed as $\mathrm{CuZnSOD}$ and the upper one as MnSOD in the gel by which incubation with $5 \mathrm{mM}$ sodium cyanide showed only the upper band. Catalase activity in nondenaturing $7 \%$ polyacrylamide gels was monitored as described previously (19). For reverse transcription-polymerase chain reaction (RT-PCR), total RNAs were prepared from cells and the first-strand cDNAs were then amplified with primers for CuZnSOD and $B$-actin.

Measurement of intracellular ROS. To determine production of intracellular $\mathrm{H}_{2} \mathrm{O}_{2}, \mathrm{O}_{2}^{-}$, and mitochondrial ROS, cells were plated on a $\mu$-slide 8 -well microscopy chamber (Ibidi, Germany) and stabilized for $24 \mathrm{~h}$. Twelve hours after GD treatment, the cells were loaded with 2, 7-dichlorofluorescein diacetate (DCFH-DA, $50 \mu \mathrm{M}$; Molecular Probes), dihydroethidium (HE, $10 \mu \mathrm{M}$; Molecular Probes) or a reduced form of MitoTracker Red CM- $\mathrm{H}_{2}$ Xros (a mitochondrial specific probe that fluoresces upon oxidation, and thereby is used to detect mitochondrial ROS, $50 \mathrm{nM}$; Molecular Probes) for 30 min under growth condition and then rinsed and soaked in phenol red-free RPMI. The cells were observed under a laser-scanning confocal microscope (LSM510, Carl Zeiss). For measurement of intracellular ROS, DCFH-DA and HE fluorescence was excited at $488 \mathrm{~nm}$ using an argon laser, and evoked emission was filtered with a 515-nm (DCFH-DA) or 515- to 605-nm (HE) band-pass filter. For measurement of mitochondrial ROS, MitoTracker Red CM-H2Xros was excited at $579 \mathrm{~nm}$, and emitted at $599 \mathrm{~nm}$.

Hoechst $33342(\mathrm{HO}) /$ propidium iodide (PI) staining. Cells were incubated either with $1 \mu \mathrm{g} / \mathrm{ml} \mathrm{HO}$ or $5 \mu \mathrm{g} / \mathrm{ml} \mathrm{PI}$ at $37^{\circ} \mathrm{C}$, $5 \% \mathrm{CO}_{2}$ for $15 \mathrm{~min}$ in the dark. Both floating and attached cells were collected by centrifugation of the medium and trypsinization, respectively. The pooled cell pellets were immediately fixed in $3.7 \%$ formaldehyde, washed with phosphate-buffered saline (PBS), resuspended, and a fraction of the suspension was centrifuged in a cytospinner (Thermo Shandon; Shandon Inc.). The slides were washed in PBS to remove excessive dye, air dried, mounted in FluroGard Antifade, and then examined under a fluorescence microscope [340/425 nm (HO), and 580/630 nm (PI); DM5000, Leica, Germany].

Annexin V-binding and propidium iodide staining. After GD treatment for the indicated times, A549 cells were incubated with of FITC-conjugated annexin V (Annexin V-FLUOS Staining Kit, Roche Molecular Biochemicals) and PI (5 $\mu \mathrm{g} / \mathrm{ml})$ for $30 \mathrm{~min}$ at room temperature in the dark. The cells were washed with ice-cold PBS, fixed with $3.7 \%$ formaldehyde, and centrifuged in a cytospinner. The slides then were mounted and observed under a fluorescence microscope (DM5000, Leica, Germany).

HMGB1 release assay. Cell culture medium was collected at the indicated time points and cells and debris were removed by centrifugation at $2400 \mathrm{x} \mathrm{g}$ for $20 \mathrm{~min}$ at $4^{\circ} \mathrm{C}$ and the supernatant first was filtered through Centricon YM-100 (Millipore) to clear the samples from cell debris and macromolecular complexes formed during clotting. Then, samples were concentrated 15-fold with Centricon YM-30 and analyzed by Western blotting with antibody to polyclonal anti-HMGB1 antibodies (BD Pharmingen). HMGB1 was identified as a 29-kDa protein.

\section{Results}

Ethyl pyruvate inhibits $H M G B 1$ release through inducing the switch of GD-induced necrosis to apoptosis. Previously, we demonstrated that A549 lung adenocarcinoma cells undergo necrotic cell death and release the inflammatory cytokine HMGB1 in response to GD (19). We examined whether EP is able to prevent GD-induced necrosis, and to suppress GDinduced secretion of HMGB1. Necrotic and apoptotic cell death were determined by $\mathrm{HO} / \mathrm{PI}$ and AV/PI double staining methods. In the HO/PI double staining method, DNA-binding dye HO is known to cross the plasma membrane of all cells, whether they are damaged or not, causing a blue fluorescence of their nuclei, while PI only penetrates cells with damaged 

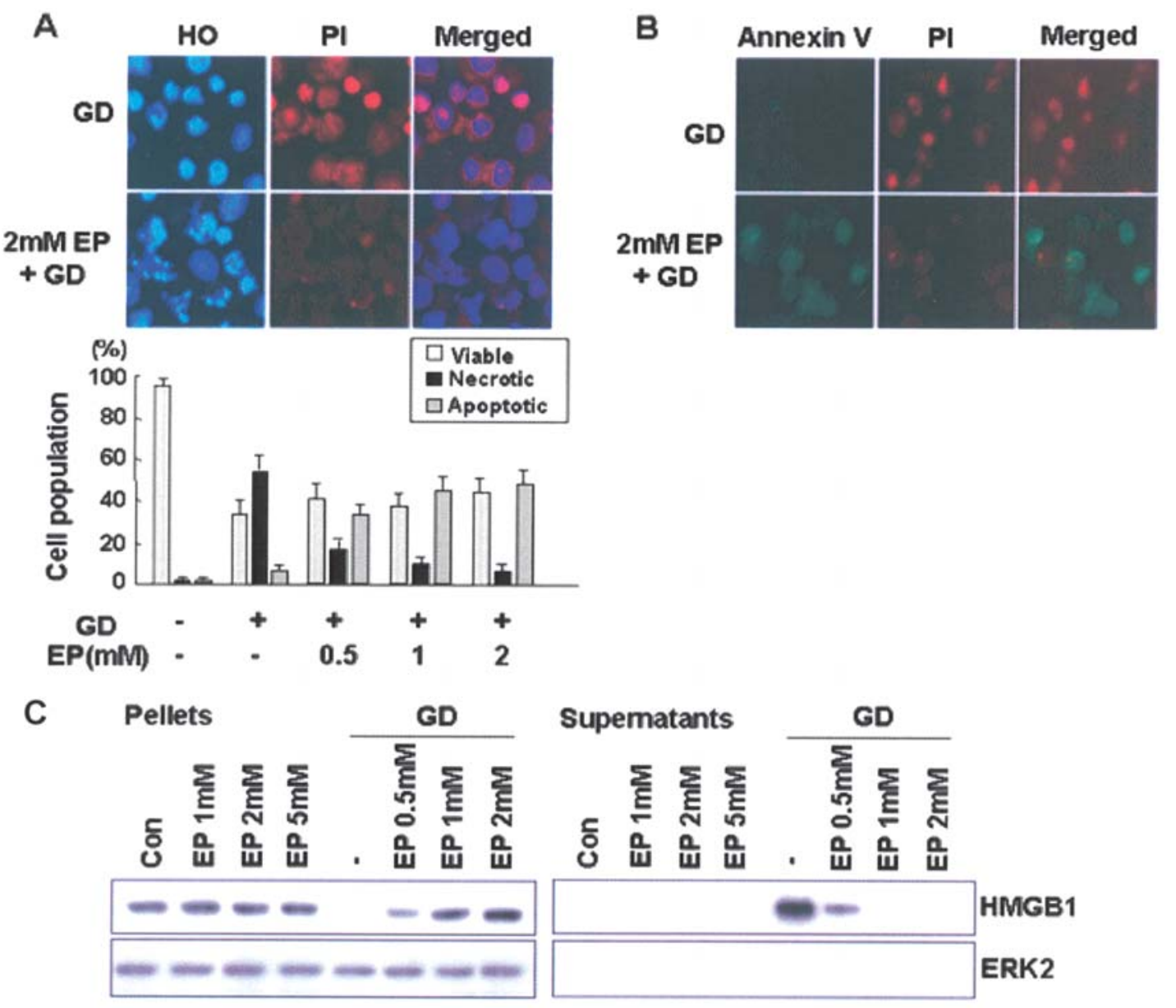

Figure 1. EP switches GD-induced necrosis to apoptosis. (A) A549 cells were cultured in normal growth medium or GD medium in the presence or absence of 0.5-2 mM EP for $24 \mathrm{~h}$. The cells were stained with HO/PI (upper panel) and apoptotic and necrotic cells were scored (lower panel). In these analyses, 500 to 800 cells in each group were counted. Data are the means \pm SEM from three independent experiments. (B) A549 cells were exposed to GD medium in the presence or absence of $2 \mathrm{mM}$ EP for $24 \mathrm{~h}$. The cells were stained with Annexin V/PI and photographed under a fluorescence microscope. (C) A549 cells were cultured in normal RPMI medium or GD medium in the presence or absence of $2 \mathrm{mM}$ EP for $24 \mathrm{~h}$ and both the cells (pellets) and the medium bathing the cells (supernatants) were prepared as described in Materials and methods and analyzed by Western blotting using antibodies to HMGB1 and ERK2.

membranes and leads to nuclear fluorescence. Thus, intact blue nuclei, condensed/fragmented blue nuclei, condensed/ fragmented pink nuclei, and intact pink nuclei were considered viable, early apoptotic, late apoptotic (secondary necrotic), and necrotic cells, respectively. In the AV/PI double staining method, exposure of phosphatidylserine (PS), which is predominantly on the inner surface facing the cytosol, is observed on the external surface of the cell membrane in the early phases of apoptosis during which the cell membrane remains intact. Changes in PS asymmetry are analyzed by measuring AV binding to the cell membrane. Staining cells simultaneously with AV (green fluorescence) and the nonvital dye PI (red fluorescence) allows the discrimination of intact $\left(\mathrm{AV}^{-} / \mathrm{PI}^{-}\right)$, early apoptotic $\left(\mathrm{AV}^{+} / \mathrm{PI}^{-}\right)$, late apoptotic $\left(\mathrm{AV}^{+} / \mathrm{PI}^{+}\right)$, and necrotic cells $\left(\mathrm{AV}^{-} / \mathrm{PI}^{+}\right)$. GD increased the population of the cells that had intact pink nuclei $(\mathrm{HO} / \mathrm{PI}$ staining, Fig. 1A upper panel) and $\mathrm{AV}^{-} / \mathrm{PI}^{+}$(AV/PI staining, Fig. 1B), confirming our previous results that GD induces necrosis (19). Treatment of EP significantly reduced the population of PI-positive cells (Fig. 1A and B). The cells exposed to GD in the presence of EP had condensed/ fragmented blue nuclei (HO/PI double staining, Fig. 1A) and $\mathrm{AV}^{+} / \mathrm{PI}^{-}$nuclei (AV/PI double staining, Fig. 1B), thus indicating that in addition to preventing necrosis, EP switches the GD-induced cell death mode to apoptosis. EP alone did not affect the cell viability (data not shown). A maximal cell death mode switch effect of EP was observed at concentrations of 0.5-2 mM (Fig. 1A lower panel). Next, we examined the effects of EP on GD-induced HMGB1 release. GD-induced HMGB1 release was suppressed by treatment with EP at a concentration of 0.5-2 mM (Fig. 1 C). In addition, EP prevented the decrease of cellular HMGB1 levels that is observed upon GD treatment. Thus, EP is likely to inhibit HMGB1 release through inducing the necrosis-to-apoptosis switch in A549 lung adenocarcinoma cells.

Apoptosis is a genetically regulated process of cell-suicide that is modulated by a variety of cellular signalling pathways (14). The central component of the apoptotic machinery is a proteolytic system consisting of caspases. Two distinct pathways upstream of the caspase cascade have been identified: the first is an extrinsic pathway, which is initiated by ligation of cell surface death receptors and caspase- 8 activation (14). The second is an intrinsic mitochondrial pathway, which is initiated by cytochrome $\mathrm{C}$ release from the mitochondria and caspase-9 activation (14). Caspase-3, a downstream effector of caspase- 8 and caspase- 9 , is a main executioner that leads to 
A

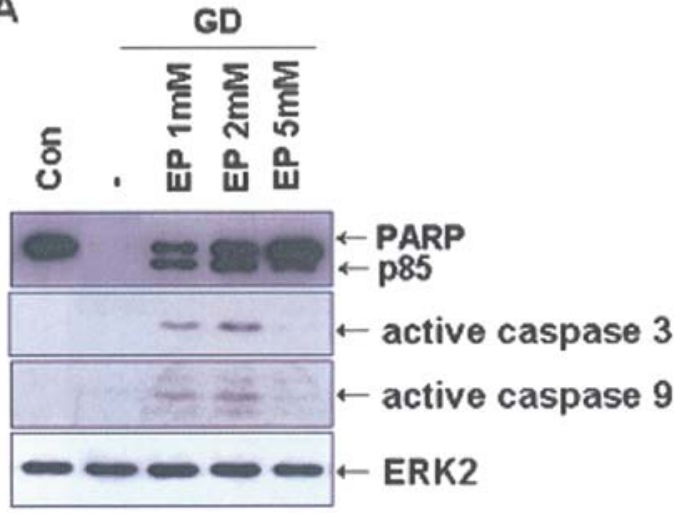

B

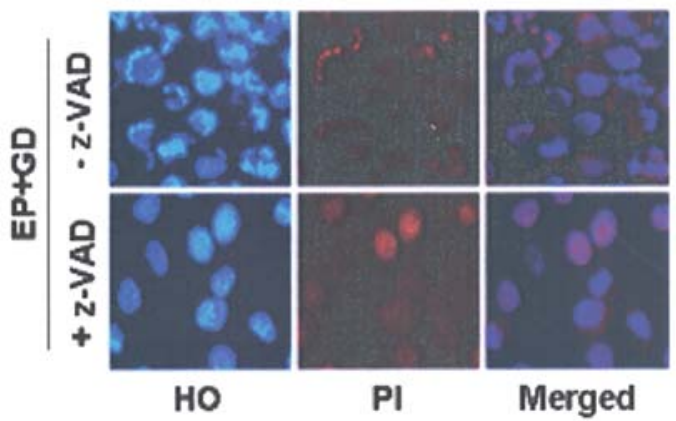

Figure 2. EP-potentiated GD-induced apoptosis is regulated by caspase-9/caspase-3 cascade. (A) A549 cells were exposed to GD medium in the presence of $\mathrm{EP}$ at concentrations of 1-5 mM for $24 \mathrm{~h}$. The cellular proteins were analyzed by SDS-PAGE and Western blotting with antibodies to PARP, active caspase-3, active caspase-9, and ERK2. (B) A549 cells were pretreated with $20 \mu \mathrm{M} \mathrm{z}$-VAD-fmk for $1 \mathrm{~h}$ and exposed to GD medium in the presence of $2 \mathrm{mM}$ EP for $24 \mathrm{~h}$. The cells were stained with $\mathrm{HO} / \mathrm{PI}$ and observed under a fluorescence microscope.
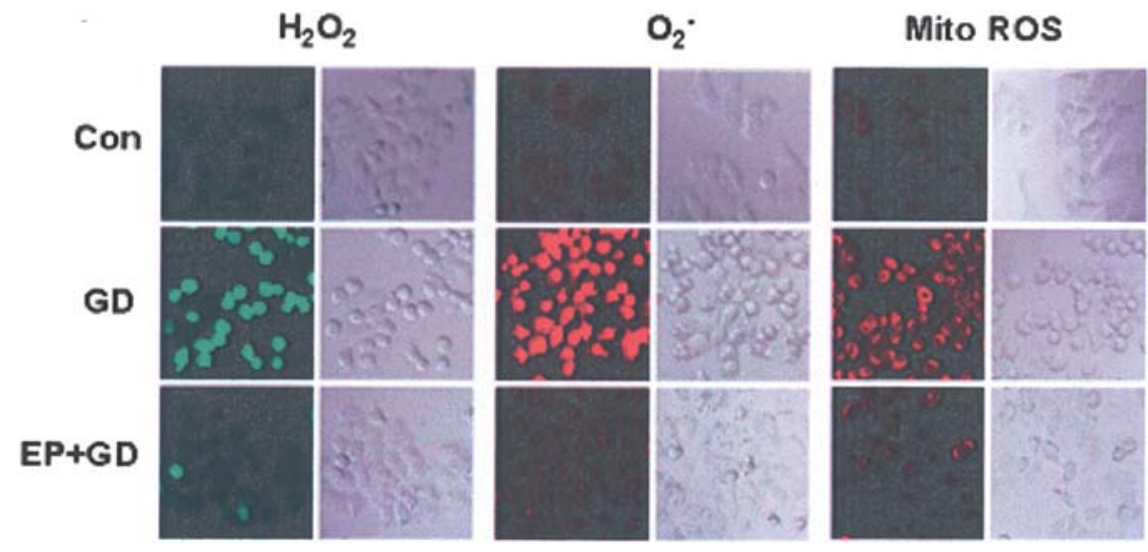

Figure 3. EP suppresses GD-induced ROS production. A549 cells were exposed to GD medium in the presence or absence of $2 \mathrm{mM}$ EP for $12 \mathrm{~h}$ and the cells were treated with DCFH-DA, HE, and $\mathrm{CMH}_{2}$ XROS for $15 \mathrm{~min}$ and intracellular $\mathrm{H}_{2} \mathrm{O}_{2}, \mathrm{O}_{2}{ }^{-}$, and mitochondrial ROS were determined under a confocal laser microscope (X200, Carl Zeiss, LSM510).

cleavage of many cellular proteins, such as poly(ADP-ribose) polymerase (PARP) and B-catenin (14). We examined whether GD-induced apoptosis is linked to either an extrinsic pathway, which activates caspase- 8 or an intrinsic mitochondrial pathway, which activates caspase-9. GD in the presence of EP activated caspase- 9 and caspase-3 (Fig. 2A), but not caspase- 8 (data not shown). Furthermore, the p85 cleavage product of PARP was also detected in cells exposed to GD in the presence of EP (Fig. 2A). A broad caspase inhibitor (z-VAD-fmk) completely suppressed EP-potentiated GD-induced apoptosis (Fig. 2B). Similarly, we have previously demonstrated that GD-induced necrosis was switched to apoptosis dependent on caspase- 9 and caspase-3, when ROS production was abolished by treatment with antioxidants including NAC and catalase and by PKC-ERK1/2-dependent SOD regulation (19).

EP suppresses GD-induced ROS production through inhibition of $G D$-induced $C u Z n S O D$ release. As demonstrated previously $(19,20)$, GD significantly enhanced production of intracellular $\mathrm{H}_{2} \mathrm{O}_{2}$ and $\mathrm{O}_{2}^{-}$(Fig. 3). The source of ROS production has been shown to be mitochondria (Fig. 3) (19-21). We further investigated whether the effects of EP are linked to regulation of GD-induced ROS production. As shown in Fig. 3, EP prevented production of intracellular $\mathrm{H}_{2} \mathrm{O}_{2}$ and $\mathrm{O}_{2}{ }^{-}$in response to GD, indicating that EP-induced cell death mode switch and inhibition of HMGB1 release may be mediated by its ability to scavenge ROS. Recently, we found that CuZnSOD was released into the extracellular space in an active form upon GD (manuscript submitted). We examined whether EP regulates levels of intracellular CuZnSOD, thereby influencing cellular damage by ROS. We show that pretreatment of EP significantly suppressed GD-induced CuZnSOD release into extracellular space without affecting CuZnSOD gene expression (Fig. 4). Thus, the cell death mode switch activity of EP may be related to its activity to prevent GD-induced CuZnSOD release.

\section{Discussion}

EP has been shown to have anti-inflammatory properties in numerous cell culture and animal studies (1-3). Treatment with EP solution could improve survival in rodent models of hemorrhagic shock and resuscitation and also down-regulate 
A
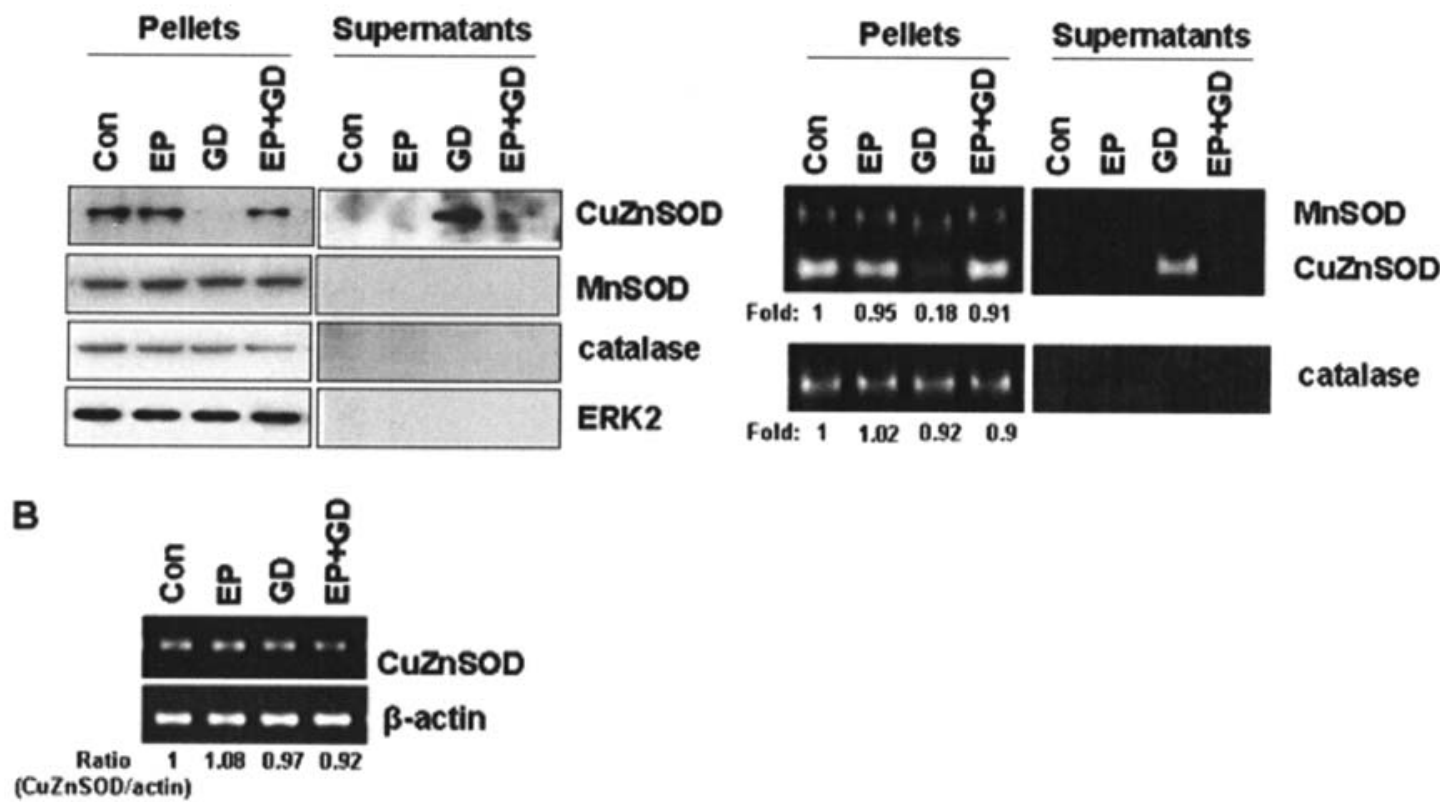

Figure 4. EP-induced cell death mode switch is related to inhibition of GD-induced CuZnSOD release. (A-B) A549 cells were incubated in normal growth medium or GD medium for $24 \mathrm{~h}$ in the presence or absence of $2 \mathrm{mM} \mathrm{EP}$. Both the cells (pellets) and the medium bathing the cells (supernatants) were prepared as described in Materials and methods and analyzed by SDS-PAGE and Western blotting with antibodies to CuZnSOD, MnSOD, catalase and total ERK2 (A, left panel). Activity assay for MnSOD, CuZnSOD, and catalase was carried out as described in Materials and methods (A, right panel). Total RNAs were prepared from cells for RT-PCR analysis and the first-strand cDNAs were then amplified with primers for CuZnSOD and B-actin (B).

a number of proinflammatory genes. Here we show that EP prevents GD-induced necrosis and switches the cell death mode to apoptosis through suppression of GD-induced $\mathrm{CuZnSOD}$ release and ROS production, thus to reduce release of the proinflammatory cytokine HMGB1. It has been well documented that EP inhibited the release of HMGB1 and TNF from endotoxin-stimulated RAW 264.7 murine macrophages $(2,22)$. HMGB 1 is actively secreted by stimulated macrophages or monocytes in a process requiring acetylation of the molecule, which enables translocation from the nucleus to secretory lysosomes. Although HMGB1 that is released from necrotic cells is molecularly different from HMGB1 that is actively secreted by macrophages since the actively secreted molecule is acetylated (2), HMGB1 could act as a cytokine by signaling both via the receptor for advanced glycated end-products (RAGE) and via members of the Toll-like receptor family, thereby initiating inflammatory responses that include the production of multiple cytokines, chemoattraction of certain stem cells, induction of vascular adhesion molecules and impaired function of intestinal epithelial cells. These data support the view that the anti-inflammatory effects of EP are related to the ability of EP to prevent HMGB 1 release by inhibiting necrotic cell death and inducing the GD-induced cell death mode switch to apoptosis.

The EP-induced cell death mode switch and inhibition of HMGB1 release are thought to be mediated, at least in part, by its ability to scavenge ROS. EP has been shown to be an effective scavenger of ROS. EP has been documented to protect PC12 cells against dopamine by suppressing intercellular oxidative stress and modulating key signal pathways of apoptosis (23). In addition, the anti-inflammatory effects of EP are related to its ability to deplete cellular GSH stores and an unusual combination of biochemical effects (inhibition of lipid peroxidation and GSH depletion) might account for them (22). We found that GD-induced necrosis depends on cytotoxic ROS including $\mathrm{O}_{2}{ }^{-}$and $\mathrm{H}_{2} \mathrm{O}_{2}$. Previously we showed that NAC (a general antioxidant) and catalase (a specific antioxidant for $\mathrm{H}_{2} \mathrm{O}_{2}$ ) prevent necrotic cell death and switched the cell death mode to apoptosis, while overexpression of $\mathrm{CuZnSOD}$ or tiron (a scavenger of $\mathrm{O}_{2}^{-}$) blocked GD-induced necrotic cell death without inducing the cell death mode switch to apoptosis (manuscript submitted). In contrast, sodium formate $\left(\mathrm{OH}^{-}\right.$scavenger) did not affect cell viability. Since tiron and $\mathrm{CuZnSOD}$ scavenge $\mathrm{O}_{2}^{-}$but promote $\mathrm{H}_{2} \mathrm{O}_{2}$ formation, $\mathrm{O}_{2}^{-}$seems to act as a major necrotic cell death-inducing ROS and excess $\mathrm{H}_{2} \mathrm{O}_{2}$ may prevent the molecular mechanism for apoptotic cell death. Thus, EP appeared to scavenge $\mathrm{O}_{2}^{-}$as well as $\mathrm{H}_{2} \mathrm{O}_{2}$. In addition, $\mathrm{CuZnSOD}$ was released into the extracellular space in an active form upon GD (Fig. 4), thereby accelerating GD-induced necrotic cell death. EP prevented CuZnSOD release, which may contribute to its ability to inhibit GD-induced necrotic cell death.

Necrosis to apoptosis switch by EP has an important implication in cancer biology. Adult cancers are frequently preceded by a long period of inflammation and necrotic cell death that are thought to promote tumor growth and angiogenesis either by increasing the probability of proto-oncogenic mutation or by action of HMGB1 (24-26). HMGB1 has been demonstrated to possess tumor promoting and angiogenenic activities in addition to acting as a proinflammatory mediator. Indeed, increased expression of HMGB1, as well as its receptor RAGE (receptor for advanced glycation end-products), has been observed in a number of tumors including hepatomas 
and prostate cancer, which correlates with invasiveness and poor outcome when RAGE is expressed in conjunction with its ligand (24). Thus, while apoptosis and antuophagy (a catabolic process initiated by starvation, whereby cells selfdigest intracellular organelles as a mechanism of cell survival or cell death, and regulated by beclin 1) suppress tumor development, necrotic cell death apparently promotes tumor growth (27). In this regard, the cell death mode switch mechanisms may provide a new strategy to control and treat tumor development. In solid tumors, necrosis is commonly found in the core region in response to oxygen and glucose depletion (OGD) due to insufficient vascularization (18-19) and OGD-induced necrotic cell death is thought to contribute to tumor growth and aggressiveness through a tumor-promoting cytokine HMGB1. Based on our results, we suggest that EP may exert tumor suppressive activities through inducing a necrosis-to-apoptosis switch and preventing release of the tumor promoting cytokine HMGB1.

\section{Acknowledgments}

This study was supported by a grant of the Korea Health 21 R\&D Project, Ministry of Health and Welfare, Republic of Korea (no. A060594), and by grants from the Ministry of Science and Technology, Korea, and the Korea Science and Engineering Foundation through the Research Center for Resistant Cells (no. R13-2003-009).

\section{References}

1. Aneja R and Fink MP: Promising therapeutic agents for sepsis. Trends Microbiol 15: 31-37, 2007.

2. Fink MP: Ethyl pyruvate: a novel anti-inflammatory agent. Crit Care Med (1 suppl): S51-S56, 2003.

3. Ulloa L, Ochani M, Yang H, Tanovic M, Halperin D, Yang R, Czura CJ, Fink MP and Tracey KJ: Ethyl pyruvate prevents lethality in mice with established lethal sepsis and systemic inflammation. Proc Natl Acad Sci USA 99: 12351-12356, 2002.

4. Hauser B, Kick J, Asfar P, Ehrmann U, Albicini M, Vogt J, Wachter U, Bruckner UB, Fink MP, Radermacher P and Bracht H: Ethyl pyruvate improves systemic and hepatosplanchnic hemodynamics and prevents lipid peroxidation in a porcine model of resuscitated hyperdynamic endotoxemia. Crit Care Med 33: 2034-2042, 2005

5. Woo YJ, Taylor MD, Cohen JE, Jayasankar V, Bish LT, Burdick J, Pirolli TJ, Berry MF, Hsu V and Grand T: Ethyl pyruvate preserves cardiac function and attenuates oxidative injury after prolonged myocardial ischemia. J Thorac Cardiovasc Surg 127: 1262-1269, 2004.

6. Kim JB, Yu YM, Kim SW and Lee JK: Anti-inflammatory mechanism is involved in ethyl pyruvate-mediated efficacious neuroprotection in the postischemic brain: Brain Res 1060: 188-192, 2005.

7. Yang R, Gallo DJ, Baust JJ, Uchiyama T, Watkins SK, Delude RL and Fink MP: Ethyl pyruvate modulates inflammatory gene expression in mice subjected to hemorrhagic shock. Am J Physiol Gastrointest Liver Physiol 283: G212-G221, 2002.
8. Yang H, Wang H, Czura CJ and Tracey KJ: The cytokine activity of HMGB1. J Leukoc Biol 78: 1-8, 2005.

9. Lotze MT and Tracey KJ: High-mobility group box 1 protein (HMGB1): nuclear weapon in the immune arsenal. Nat Rev Immunol 5: 331-342, 2005.

10. Scaffidi P, Misteli T and Bianchi ME: Release of chromatin protein HMGB1 by necrotic cells triggers inflammation. Nature 418: 191-195, 2002.

11. Zong WX and Thompson CB: Necrotic death as a cell fate. Genes Dev 20: 1-15, 2006.

12. Syntichaki P and Tavernarakis N: Death by necrosis. Uncontrollable catastrophe, or is there order behind the chaos? EMBO Rep 3: 604-609, 2002.

13. Martindale JL and Holbroo NJ: Cellular response to oxidative stress: signaling for suicide and survival. J Cell Physiol 192: 1-15, 2002.

14. Hengartner MO: The biochemistry of apoptosis. Nature 407: 770-776, 2000.

15. Chiarugi A: 'Simple but not simpler': toward a unified picture of energy requirements in cell death. FASEB J 19: 1783-1788, 2005.

16. Armstrong JS: Mitochondrial membrane permeabilization: the sine qua non for cell death. BioEssays 28: 253-260, 2006.

17. Mates JM and Sanchez-Jimenez F: Antioxidant enzymes and their implications in pathophysiologic processes. Front Biosci 4: D339-D345, 1999.

18. Gatenby RA and Gillies RJ: Why do cancers have high aerobic glycolysis? Nat Rev Cancer 4: 891-899, 2004.

19. Kim CH, Han SI, Lee SY, Youk HS, Moon JY, Duong HQ, Park MJ, Joo YM, Park HG, Kim YJ, Yoo MA, Lim SC and Kang HS: Protein kinase C-ERK1/2 signal pathway switches glucose depletion-induced necrosis to apoptosis by regulating superoxide dismutases and suppressing reactive oxygen species production in A549 lung cancer cells. J Cell Physiol 211: 371-385, 2007.

20. Ahmad IM, Aykin-Burns N, Sim JE, Walsh JE, Higashikubo R, Buettner GR, Venkataraman S, Mackey MA, Flanagan SW, Oberley LW and Spitz DR: Mitochondrial $\mathrm{O}_{2}{ }^{*-}$ and $\mathrm{H}_{2} \mathrm{O}_{2}$, mediate glucose deprivation-induced stress in human cancer cells. J Biol Chem 280: 4254-4263, 2005.

21. Muller FL, Liu Y and Van Remmen H: Complex III releases superoxide to both sides of the inner mitochondrial membrane. J Biol Chem 279: 49064-49073, 2004.

22. Song M, Kellum JA, Kaldas H and Fink MP: Evidence that glutathione depletion is a mechanism responsible for the antiinflammatory effects of ethyl pyruvate in cultured lipopolysaccharide-stimulated RAW 264.7 cells. J Pharmacol Exp Ther 308: 307-316, 2004

23. Wang LZ, Sun WC and Zhu XZ: Ethyl pyruvate protects PC12 cells from dopamine-induced apoptosis. Eur J Pharmacol 508: 57-68, 2005.

24. Vakkila $J$ and Lotze MT: Inflammation and necrosis promote tumour growth. Nat Rev Immunol 4: 641-648, 2004.

25. Taguchi A, Blood DC, del Toro G, Canet A, Lee DC, Qu W, Tanji N, Lu Y, Lalla E, Fu C, Hofmann MA, Kislinger T, Ingram M, Lu A, Tanaka H, Hori O, Ogawa S, Stern DM and Schmidt AM: Blockade of RAGE-amphoterin signalling suppresses tumour growth and metastases. Nature 405: 354-360, 2000.

26. Schlueter C, Weber H, Meyer B, Rogalla P, Roser K, Hauke S and Bullerdiek J: Angiogenetic signaling through hypoxia: HMGB1: an angiogenetic switch molecule. Am J Pathol 166: 1259-1263, 2005.

27. Degenhardt K, Mathew R, Beaudoin B, Bray K, Anderson D, Chen G, Mukherjee C, Shi Y, Gelinas C, Fan Y, Nelson DA, Jin $\mathrm{S}$ and White E: Autophagy promotes tumor cell survival and restricts necrosis, inflammation, and tumorigenesis. Cancer Cell 10: 51-64, 2006. 